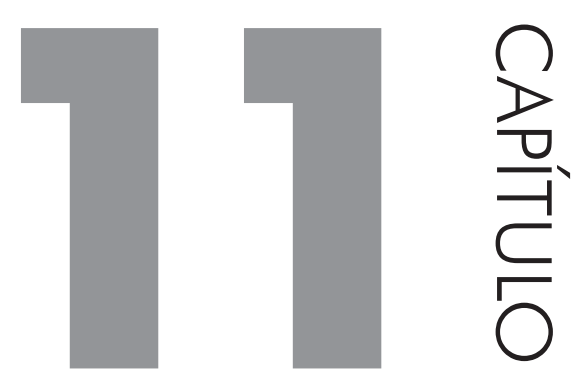

\title{
O USO E A ORDEM DOS CLÍTICOS NA ESCRITA DE ESTUDANTES DA CIDADE DO RIO DE JANEIRO
}

\section{ANA CARLA MORITO MACHADO'1}

\section{INTRODUÇÃO}

A questão da colocação pronominal e do uso dos pronomes continua, ao longo dos anos, inquietando profissionais da Língua Portuguesa em sala de aula no que tange ao estabelecimento de uma norma padrão e o uso cotidiano dos clíticos, na fala e na escrita. Os trabalhos relativos ao ensino de Língua Portuguesa e a seu emprego real tendem a mostrar as diferenças entre o uso e o que é proposto no chamado ensino de gramática. O presente artigo tem por objetivo principal apresentar resultados de um estudo (MACHADO, 2006) em que se observou o uso e a ordem dos clíticos pronominais no desempenho escrito de estudantes dos níveis Fundamental e Médio de Ensino, de modo a determinar, com base nos pressupostos teórico-metodológicos da Sociolinguística Variacionista, os fatores linguísticos e extralinguísticos que condicionam o uso da ênclise em redações

\footnotetext{
Silvia Figueiredo Brandão atuou, em parceria com Silvia Rodrigues Vieira, como minha orientadora do trabalho de Mestrado, cujos resultados sintetizo no presente artigo. Dessa experiência resulta muito do que busco hoje na experiência profissional em escolas do Rio de Janeiro: uma atuação dedicada e comprometida com o ensino público e de qualidade.
} 
escolares. Ao observar as formas alternantes empregadas pelos estudantes, a investigação também avaliou a produtividade dos clíticos acusativos no corpus, a fim de dar a real dimensão desses elementos linguísticos em relação às outras estratégias de preenchimento de objeto direto.

Tendo em vista que a próclise constitui opção preferencial na modalidade oral do Português do Brasil, testaram-se, entre outras, as hipóteses (a) de que o processo de ensino/aprendizagem implicaria mudança(s) no desempenho linguístico dos alunos no que se refere à produtividade e à ordem dos clíticos, sobretudo na modalidade escrita; e (b) de que, nas redações escolares, a maior frequência de uso da ênclise nos contextos especificados pela norma idealizante estaria vinculada ao maior grau de escolaridade do estudante.

Ao buscar apontar os contextos favorecedores da ênclise por parte dos estudantes, procura-se compreender os motivos de sua opção, tendo em vista, de um lado, que esta é uma variante pouco produtiva na fala, circunscrevendo-se, conforme demonstram pesquisas anteriores, a contextos específicos, e, de outro, que os alunos, no processo de escolarização, são apresentados a um modelo que não praticam nem faz parte dos dados a que naturalmente são expostos na aquisição da língua.

\section{BREVE REVISÃO DA LITERATURA²: A ORDEM DOS CLÍTICOS PRONOMINAIS}

Na Língua Portuguesa, mais especificamente no Português do Brasil, há que se observar como a ordem dos clíticos é tratada, tanto na perspectiva tradicional, quanto na dos estudos linguísticos. Para tanto, o estudo verificou as regras que norteiam o ensino, a partir das gramáticas de Bechara (2004 [1999]), Rocha Lima (2003 [1972]) e Cunha; Cintra (1985), além de tratar da observação das regras em uso no Português do Brasil, com base nos trabalhos de Pereira (1981), Lobo (1992), Schei (2003), Vieira (2002) e Vieira; Nunes; Barboza (2004). Os referidos estudos observaram, de modo geral, ser a próclise a norma de uso na modalidade oral do Brasil, enquanto na escrita o comportamento varia bastante, tendo a ênclise expressiva produtividade. Desse modo, o desempenho linguístico dos alunos, menos distante do modelo oferecido na norma padrão no que se refere à produtividade e à ordem dos clíticos - sobretudo na modalidade escrita -, ocorreria pela influência que o processo de ensino/aprendizagem exerceria sobre a escrita escolar.

2 Nesta seção, apresentam-se as orientações de gramáticas tradicionais e os resultados gerais de investigações realizadas anteriormente a 2006 e que contemplavam a fala e/ou a escrita brasileiras. 
De acordo com a perspectiva tradicional com base em Cunha; Cintra (1985), o pronome - que pode estar enclítico ou proclítico em relação ao verbo - tem como posição lógica, normal, a ênclise, já que o pronome átono funciona como objeto direto ou indireto do verbo. Há, entretanto, uma lista de ocasiões em que se deve dar preferência à próclise devido à ação dos elementos proclisadores ou atratores. Os autores tratam, entretanto, como legítima a ênclise nos casos em que ocorre pausa entre o atrator e o verbo. A mesóclise é a posição normal do pronome átono quando o verbo se apresenta nas formas de futuro do presente e futuro do pretérito, desde que não antecedido de elemento proclisador.

Rocha Lima (2003 [1972], p. 450) inicia suas considerações afirmando que a posição normal dos pronomes átonos é "depois do verbo". A ênclise se dá nos casos em que o verbo abre o período; quando o sujeito - substantivo ou pronome - vier antes do verbo, desde que não seja constituído de palavra negativa; e nas orações coordenadas assindéticas. Após essas considerações, o gramático faz a seguinte observação: "em qualquer desses casos, pode, contudo, por puro arbítrio ou gosto, ocorrer anteposição, salvo em início de período”. (ROCHA LIMA, 2003 [1972], p. 451). Após classificar a ênclise como posição "normal”, o autor lista como contextos obrigatórios para o uso da próclise os seguintes casos: orações negativas iniciadas por palavras negativas; orações exclamativas ou optativas iniciadas por palavras desses tipos; orações interrogativas começadas por pronomes ou advérbios interrogativos; orações subordinadas; verbos antecedidos de advérbios e pronomes indefinidos, sem pausa. No caso das formas nominais, propõe que a ênclise é obrigatória com infinitivo, sendo facultativa quando este vier precedido por preposição, e também com gerúndio, exceto quando antecedido de preposição ou de advérbio.

Bechara (2004 [1999]) inicia suas observações com o caso particular da forma $o$ e variantes, propondo que a colocação dos pronomes átonos e do demonstrativo o é questão de fonética sintática. Além disso, considera "falsa" a questão da atração supostamente exercida por palavras como o não e o que, além de certas conjunções e diversos outros vocábulos. O autor recorre a Said Ali, afirmando que, graças a ele, se passou a considerar o tema da ordem dos clíticos privilegiando sua face fonológica. Com o desenvolvimento dos estudos sobre vocábulos átonos e tônicos, chegou-se à conclusão de que muitas das regras estabelecidas pelos puristas ou estavam erradas ou se aplicavam em especial ao falar lusitano. Ao propor algumas normas que seriam usadas na linguagem escrita e falada das pessoas cultas, sugere que, não havendo infração a tais normas, o problema se relacionaria a uma "questão pessoal de escolha", que atenderia às exigências da eufonia. Afirma, ainda, a urgência de se afastar a ideia de que a colocação brasileira seria inferior à portuguesa, com uma citação de Ali: “a pronúncia brasileira diversifica da lusitana; daí resulta que a colocação pronominal em nosso falar espontâneo não coincide perfeitamente com a do falar dos portugueses” 
(apud BECHARA, 2004, p. 587). O autor conclui suas considerações sobre a colocação pronominal admitindo que o fenômeno toma feições particulares no Brasil, que devem ser explicadas levando em consideração um conjunto de fatores que as envolvem, como o rítmico, o estilístico, o histórico, dentre outros.

A despeito do que as gramáticas normativas preconizam, diversos pesquisadores verificam o comportamento particular da variedade brasileira em diferentes amostras. A diferenciação entre o que se prescreve e o que efetivamente se usa, no que diz respeito à ordem dos clíticos pronominais, é sentida quando se tenta seguir, na escola, uma norma que não faz parte da realidade linguística dos alunos. A esse respeito, Pereira (1981) - primeira pesquisa variacionista do tema com a fala brasileira, até onde se tem notícia - compara a fala e a escrita, e propõe que a língua falada serviria para "detectar a tendência natural na colocação dos pronomes" (p. 4), já que a modalidade escrita se mostraria mais conservadora. A autora analisa um corpus oral constituído por informantes de diversas idades, pertencentes a diferentes níveis de escolaridade - de analfabetos ou semianalfabetos até pessoas com formação universitária - e procedentes de várias regiões do país, principalmente do Rio de Janeiro, Minas Gerais e Alagoas. A autora faz uma descrição detalhada das características de cada informante e observa que, nas entrevistas, a variação se dá somente em termos de próclise e ênclise. Verifica que, quando se cruzam as variáveis idade e escolaridade, a escolaridade tem atuação mais fraca na escolha da colocação pronominal, e que, ainda mais importante, segundo sua hipótese, seria a questão da formalidade e da atividade profissional. De modo geral, o estudo demonstra que, na fala, a próclise é o processo mais geral, e a ênclise estaria restrita a determinadas formas linguísticas cristalizadas.

Lobo (1992) buscou oferecer mais uma contribuição para a resolução do problema da diferenciação entre o que é prescrito e o que é usado no que se refere à questão da colocação pronominal. A autora considera esse aspecto muito importante para a diferenciação das variedades brasileira e europeia do Português. Também alude à necessidade de se saber qual teria sido a situação da língua no período em que começa a vigência do Português no Brasil, em situação de língua transplantada.

De modo geral, o estudo demonstra que o padrão de colocação do clítico no $\mathrm{PB}$ contemporâneo culto oral se caracteriza por ser variável em quase todos os contextos considerados, com nítida preferência pela variante pré-verbal. As variáveis extralinguísticas controladas na análise - faixa etária, o local de origem dos informantes, e a (des)obediência à norma-padrão - não demonstraram comportamento relevante no condicionamento do fenômeno. No que se refere ao condicionamento estrutural, o estudo oferece as seguintes conclusões: (i) a próclise foi categórica nos enunciados com verbo precedido por SN sujeito pronome pessoal e por SAdv de negação; (ii) são condicionamentos bastante favoráveis à próclise: orações subordi- 
nadas desenvolvidas, enunciados com verbo precedido por SN sujeito nominal e por Sadvs / Spreps circunstanciais (sobretudo quando não se separam do verbo por pausa); (iii) A colocação pós-verbal do clítico foi categórica no contexto de clítico acusativo de terceira pessoa o, a (s) diante de infinitivo verbal; (iv) são condicionamentos bastante favoráveis à ênclise: posposição do clítico se ao verbo, como estratégia para indicar sujeito semanticamente indeterminado; e orações subordinadas reduzidas de gerúndio. (cf. LOBO, 1992, p. 210). Segundo a autora, as estruturas com gerúndio, clítico acusativo de $3^{a}$ pessoa junto ao infinitivo e clítico "se" nas construções de sujeito indeterminado destacam-se como "ilhas de resistência ao padrão observado para o PB culto contemporâneo" (p. 211).

Vieira (2002) estuda a ordem dos clíticos em três variedades do Português: a europeia, a brasileira e a moçambicana, nas modalidades oral e escrita com base em dados de pronomes átonos em lexias verbais simples e complexas. A autora desenvolve sua pesquisa - com base nos princípios da Sociolinguística Variacionista e da Fonética Acústica - considerando a interface morfologia-sintaxe-fonologia, pois acredita ser esse tema um dos mais produtivos para que se observe a interinfluência dos diversos planos da língua. Estudando tanto dados de fala como de escrita no Português do Brasil, parte da hipótese de que a colocação pré-verbal e a pós-verbal podem figurar como formas alternantes para um mesmo contexto estrutural. Dessa forma, busca identificar os elementos favorecedores de cada variante, sejam eles de natureza linguística ou extralinguística.

$\mathrm{Na}$ variedade brasileira falada, o estudo confirma a opção pela próclise (89\%), apresentando, ainda, com base nas variáveis condicionadoras do fenômeno, os contextos em que a ênclise (11\%) foi registrada. Assim, poucos contextos determinam a concretização da ênclise no PB oral: (i) de ordem linguística - os pronomes $o / a(s)$ e $s e$, este principalmente em estrutura de indeterminação/apassivação e, com menos expressividade, os contextos sem a presença de um tradicional "atrator"; e (ii) de ordem extralinguística - a fala de indivíduos com mais de 55 anos de idade (Cf. VIEIRA, 2002, p. 232). Na modalidade escrita (em crônicas jornalísticas), além do tipo de clítico, passa a atuar, com expressividade, a variável presença de "atrator" e distância entre o "atrator" e o grupo clítico-verbo. $\mathrm{Na}$ ausência de um atrator ou em contexto antecedido de conjunção coordenativa ou locução adverbial, especialmente quando distantes do clítico, este tende a aparecer em ênclise. Quanto ao tipo de oração, quanto mais independente for a construção em que se encontra o clítico, maior a produtividade da ênclise.

Considerando o contexto de aprendizagem, Vieira, Nunes e Barboza (2004) investigaram a ordem dos clíticos pronominais analisando 268 redações das últimas séries dos níveis Fundamental, Médio e Superior de ensino, aplicadas em escolas do Rio de Janeiro. O estudo contou com 869 ocorrências de pronomes átonos. Quanto ao uso do clítico, as autoras observam que seu número aumenta 
de acordo com o aumento da escolaridade. O corpus utilizado registrou percentuais de ênclise de $7 \%, 18 \%$ e $52 \%$, respectivos aos níveis estudados. Como se pode observar, a opção pela próclise é bem maior no Ensino Fundamental, chamada pelas autoras de estágio inicial. Duas variáveis exerceram maior influência sobre o condicionamento da ênclise: tipo de clítico e presença de "atrator". O estudo demonstra que a aprendizagem da variante pós-verbal na escrita escolar começa pelos contextos mais artificiais considerando-se a modalidade oral do PB, como, por exemplo, aqueles que se valem dos pronomes $o, a(s)$.

De acordo com Lucchesi (2002), a vulgarização do ensino público e o fenômeno dos meios de comunicação de massa, nas últimas décadas, acabaram por consolidar uma tendência à variação na norma culta, que, assim, se afasta cada vez mais do padrão normativo, o qual, em consonância com o projeto de exclusão social das elites brasileiras, continua a reproduzir os modelos europeus, alterando apenas sua fundamentação retórica (cf. PAGOTTO, 1998). Lucchesi (2002) afirma, citando Pagotto (1998), que é exatamente na tentativa de estabelecimento de um padrão linguístico nacional que se revela o paradoxo projeto político das elites brasileiras, dando continuidade à exclusão de uma grande parcela da população, enquanto uma pequena minoria assume a liderança do processo. Em toda sociedade, entrecruzam-se um critério intralinguístico de correção e um critério extralinguístico ou social, fato que pode ser verificado através da utopia escolar em atingir a norma padrão citada pelo autor - uma abstração -, enquanto seus falantes buscam a norma culta, a concretização. As contradições da realidade social refletem-se no plano das normas linguísticas. Ao mesmo tempo em que se observa, no plano objetivo dos padrões coletivos de comportamento verbal, uma tendência ao nivelamento das duas normas linguísticas, o estigma ainda recai sobre as variantes características da norma popular.

\section{FUNDAMENTOS TEÓRICO-METODOLÓGICOS}

O estudo ora sintetizado (MACHADO, 2006) tem por objetivo contribuir para a descrição da norma empregada por brasileiros em fase escolar. Para cumprir o propósito estabelecido e vincular a questão satisfatoriamente ao debate sobre a norma, desenvolveu-se a pesquisa com base nos pressupostos teórico-metodológicos da Sociolinguística Quantitativa, de inspiração laboviana. A Sociolinguística constitui um campo interdisciplinar entre a Linguística e a Sociologia que estuda o efeito de aspectos sociais e linguísticos sobre a maneira como se usa a linguagem, incluindo suas normas culturais e os contextos de uso dos falantes. Nos estudos sociolinguísticos, essa opção do falante, que ora se aplica, ora não, resulta no que é denominado regra variável. A investigação da regra variável pressupõe que as variantes se encontrem em um mesmo contexto e com o mesmo valor de verdade ou mesmo valor funcional. Para a depreensão e o entendimento 
de uma determinada regra variável, o estudo leva em consideração os diversos fatores que possam influenciar a escolha dos falantes por uma das variantes.

No caso deste estudo em particular, postulou-se como hipótese a preferência dos estudantes pela próclise, apesar da intensa pressão normativa (exercida pela escola) em favor do uso da ênclise em determinados contextos. Uma vez que tanto a posição pré-verbal quanto a pós-verbal constitui construções possíveis em relação à ordem dos clíticos no mesmo contexto sintático, podem-se considerar ambas como legítimas variantes linguísticas. Tendo em vista a suposição de que a variante pós-verbal seja a menos produtiva, optou-se por determinar os fatores que a favorecem; em outras palavras, a ênclise é o valor de aplicação.

A escolha de redações condiz com o objetivo de investigar a interferência direta da escola na questão da colocação pronominal, fenômeno mais abordado, no caso da sincronia contemporânea, em textos literários (SCHEI, 2002), em textos jornalísticos (VIEIRA, 2002) e em documentos e inquéritos (LOBO, 1992). Foram aplicados e coletados textos narrativos e dissertativos em escolas públicas e privadas. Constituiu-se um corpus de 590 ocorrências de clíticos junto a lexias verbais simples, selecionadas de 360 redações de alunos da quarta e oitava séries do Ensino Fundamental e da terceira série do Ensino Médio, sendo 180 de escolas públicas e 180 de escolas privadas (15 meninos e 15 meninas em cada série de cada escola). Buscou-se, de certa forma, priorizar sua orientação metodológica, o que se deu por meio da variável tipo de escola - pública/privada -, partindo-se do princípio de que a escola pública estaria mais comprometida com os PCN (Parâmetros curriculares nacionais) e, portanto, aberta a propostas de ensino mais inovadoras. Embora não se tivesse como ponto de partida a variável faixa etária dos alunos, a oposição entre as séries escolhidas permitiu delimitar que os alunos da quarta série do Ensino Fundamental teriam de 9 a 12 anos, os da oitava série, de 14 a 16 anos, e os da terceira série do Ensino Médio, de 17 a 19 anos $^{3}$.

A análise dos resultados gerais suscitou a observação mais aprofundada de um aspecto linguístico que não constituía, a princípio, o tema da pesquisa, qual seja o da questão da produtividade dos clíticos pronominais no Português do Brasil, especialmente os acusativos (o, a, os, as) e dativos (lhe) de $3^{\mathrm{a}}$ pessoa. Tendo em vista que o preenchimento do objeto direto pode se dar, além do clítico (encontrei-o), por um sintagma nominal (encontrei o professor), por anáfora zero (encontrei $\varnothing$ ) e, ainda, por um pronome tradicional do caso reto (encontrei ele),

3 À época da realização da pesquisa, ainda não tinha ocorrido a alteração no Ensino Fundamental. A aprovação da lei 11.274, em fevereiro de 2006, que mudou a duração do ensino fundamental de oito para nove anos, transformou o último ano da educação infantil no primeiro ano do ensino fundamental. Desta forma, onde se lê quarta série, leia-se quinto ano e onde se lê oitava série, leia-se nono ano do EF. 
constituiu-se, à parte, uma amostra com os contextos em que o aluno teria por opção um clítico, a fim de avaliar a produtividade dos pronomes átonos escolhidos e das outras opções de preenchimento do objeto na escrita escolar.

Quanto à ordem dos clíticos pronominais, procedeu-se à identificação dos contextos favorecedores da variante pós-verbal, já que a intenção do trabalho é justamente a de observar o impacto da divulgação da norma idealizante no meio escolar.

\section{ANÁLISE DOS DADOS}

Embora o tema central do trabalho gire em torno da aprendizagem e do uso dos clíticos no que se refere à ordem, observou-se também, conforme já se esclareceu, a distribuição dos dados de pronomes átonos de $3^{a}$ pessoa em relação a outras variantes de preenchimento do objeto direto anafórico. Esses resultados, relativos à produtividade, apresentam um panorama geral do uso desses pronomes nas redações escolares de modo a dar a real dimensão de seu emprego nos textos, tendo em vista o fato de pesquisas sobre o tema virem demonstrando sua baixa frequência no $\mathrm{PB}$. O propósito é identificar que estratégia de preenchimento do objeto é mais produtiva, a fim de se relativizar a presença dos clíticos de terceira pessoa em relação às demais possibilidades de preenchimento.

Para a análise da expressão do objeto direto e a produtividade dos clíticos, a amostra analisada contou com 396 dados, também oriundos das 360 redações (180 textos narrativos e 180 textos dissertativos) de alunos de escolas públicas e privadas, da cidade do Rio de Janeiro. Observou-se o uso de clíticos acusativos em oposição a outros tipos de preenchimento. As estratégias de preenchimento observadas estão presentes na tabela a seguir:

Tabela 1 Distribuição geral dos dados: estratégias de preenchimento do objeto direto.

\begin{tabular}{|l|c|c|}
\hline \multicolumn{1}{|c|}{ TIPO DE PREENCHIMENTO } & OCORRÊNCIAS & VALORES PERCENTUAIS \\
\hline Mesmo SN & $66 / 396$ & $17 \%$ \\
\hline Outro SN & $23 / 396$ & $06 \%$ \\
\hline Pronome reto & $78 / 396$ & $20 \%$ \\
\hline Clítico acusativo & $147 / 396$ & $37 \%$ \\
\hline Categoria vazia & $82 / 396$ & $21 \%$ \\
\hline
\end{tabular}

Fonte: Machado (2006: 65).

De modo geral, chama a atenção o fato de a estratégia de preenchimento do objeto por clítico obter o índice mais alto: $37 \%$. As demais variantes - se forem 
amalgamados os fatores que abrangem sintagma nominal - ocorrem em cerca de $20 \%$ (23\%: SNs; $20 \%$ : pronome reto; e $21 \%$ : categoria vazia.).

Para o estudo específico da ordem dos clíticos pronominais, computaram-se 590 ocorrências de formas átonas. Com relação à frequência de uso, verificou-se um aumento gradativo na utilização dos mesmos por parte dos alunos - conforme demonstrado na análise dos dados de produtividade. O uso dos clíticos aumenta sensivelmente de acordo com o aumento da escolaridade.

Tabela 2 Frequência de uso dos clíticos quanto à escolaridade do informante.

\begin{tabular}{|l|c|c|}
\hline \multicolumn{1}{|c|}{ SÉRIE } & OCORRÊNCIAS & VALOR PERCENTUAL \\
\hline Quarta série & $42 / 590$ & $07 \%$ \\
\hline Oitava série & $184 / 590$ & $31 \%$ \\
\hline Terceiro ano & $364 / 590$ & $62 \%$ \\
\hline
\end{tabular}

Fonte: Machado (2006: 106).

A hipótese geral investigada é a de que a ordem dos clíticos praticada nas redações escolares não corresponderia aos padrões preconizados pela gramática tradicional, sobretudo no que toca ao emprego da ênclise, já que a próclise seria preferencialmente usada na escrita dos estudantes. De fato, computadas as 590 ocorrências, verificou-se que 118 são de pronomes enclíticos (20\%) e 472 de pronomes proclíticos $(80 \%)$. Percebe-se, portanto, a preferência dos estudantes pelo uso da variante pré-verbal em diversos contextos morfossintáticos, tendência já apontada em estudos anteriores.

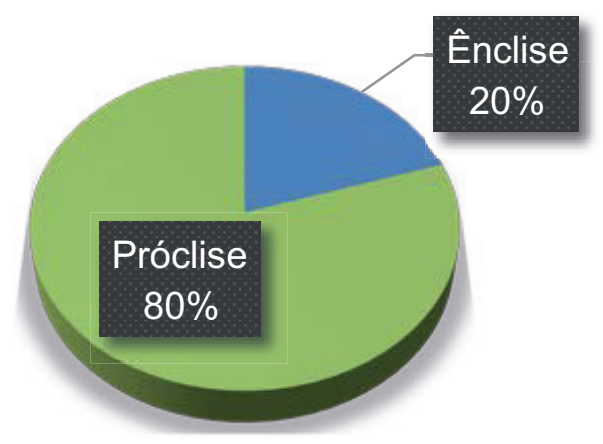

Gráfico 1 A ordem dos clíticos pronominais em redações escolares com base em 590 dados. Fonte: Machado (2006: 91).

A fim de se entender como, apesar do baixo registro de clíticos em posição pós-verbal, a ênclise passa a se manifestar na escrita dos estudantes, observou-se, sobretudo, a influência das variáveis Escolaridade e Tipo de clítico. 
Para melhor visualização da influência do grau de instrução do aluno, deve-se observar, na tabela a seguir, o efeito de cada fator expresso em índices relativos:

Tabela 3 Aplicação da ênclise quanto à escolaridade do informante.

\begin{tabular}{|l|c|c|c|}
\hline \multicolumn{1}{|c|}{ SÉRIE } & OCORRÊNCIAS & VALORES PERCENTUAIS & PESOS RELATIVOS \\
\hline Quarta série & $10 / 42$ & $23 \%$ & .49 \\
\hline Oitava série & $22 / 184$ & $11 \%$ & .30 \\
\hline Terceiro ano & $86 / 364$ & $23 \%$ & .60 \\
\hline
\end{tabular}

Fonte: Machado (2006: 106).

A variável série escolar demonstra que, ainda que não de forma crescente, o grau de instrução exerce certa influência sobre a aprendizagem das normas da ordem dos clíticos, visto que, ao fim da $3^{\mathrm{a}}$ série do Ensino Médio, o favorecimento ao uso da ênclise se dá de forma mais expressiva (.60). Percebe-se, no entanto, que tal influência não é suficiente para que a próclise, como já se esperava, mesmo ao fim do ciclo escolar, deixe de constituir o uso preferencial por parte desses estudantes em diversos contextos morfossintáticos.

Aprofundando a análise de uso da ênclise, observou-se que essa produtividade da ênclise estava intimamente relacionada ao tipo de clítico em questão, conforme se verifica no quadro a seguir:

Tabela 4 Frequência de uso da ênclise quanto ao tipo de clítico.

\begin{tabular}{|l|c|c|}
\hline \multicolumn{1}{|c|}{ TIPO DE CLÍTICO } & OCORRÊNCIAS & VALORES PERCENTUAIS \\
\hline o, a, os, as & $64 / 147$ & $43 \%$ \\
\hline se inerente & $24 / 166$ & $14 \%$ \\
\hline se apassivador & $04 / 24$ & $16 \%$ \\
\hline se reflexivo & $13 / 88$ & $14 \%$ \\
\hline se indeterminador & $03 / 13$ & $23 \%$ \\
\hline me & $02 / 85$ & $02 \%$ \\
\hline Ihe $(s)$ & $07 / 34$ & $20 \%$ \\
\hline nos & $0 / 25$ & $0 \%$ \\
\hline vos & - & - \\
\hline te & 0107 & $12 \%$ \\
\hline
\end{tabular}

Fonte: Machado (2006: 97). 
Mesmo sendo a ênclise pouco produtiva no corpus em geral, na análise percentual dos dados, chama a atenção o índice referente a $o, a$, os, $a s$, que aparece com $43 \%$ de frequência de ênclise, seguido do se indeterminador e do lhe. Apesar dos baixos dados de ênclise em termos percentuais, a projeção estatística, no que se refere ao peso dos fatores no favorecimento à variante pós-verbal, confirma as hipóteses estabelecidas: o pronome $o, a(s) \_a p a r e c e$ como o clítico mais fortemente favorecedor da ênclise, seguido de lhe e de se. Como elementos fortemente desfavorecedores da ênclise, figuram os pronomes de primeira e segunda pessoas.

Embora, de acordo com os estudos do preenchimento do objeto, os clíticos $o, a(s)$ sejam formas em extinção na fala (e, portanto, segundo a hipótese deste trabalho, pouco produtivos na escrita), ao que parece, Monteiro (1994) tem razão ao afirmar que seus alomorfes continuam "vivos como nunca" (p. 195). Na pesquisa que ora se apresenta, parte-se do princípio de que a escola busca implementar, pelo menos na realidade representada pela amostra sob análise, não só o clítico acusativo de terceira pessoa, mas também este na posição enclítica.

Dessa forma, pelo menos com relação à escrita dos estudantes, é preciso fundamentar a prática pedagógica nas diferenças entre a escrita e a fala, e o que se espera é que essa diferença seja relevante para o ensino da gramática, no intuito de se buscar um ensino mais efetivo, calcado naquilo que Lucchesi (2002) chama de "normal", como é o uso da próclise por nossos alunos. Não se trata somente de estudar a colocação pronominal, mas também de levar o aluno a reconhecer os clíticos como recursos anafóricos importantes para a construção de um texto, sem, no entanto, colocar fala e escrita em patamares de importância e correção diferentes, como se, na fala, tudo fosse permitido e, na escrita, nada.

A respeito do ensino da ordem, manifesta-se Vieira (2004), em artigo intitulado "O ensino da colocação pronominal: prescrição e uso". Deve-se, segundo a autora, ver, no estudo da colocação pronominal, "uma oportunidade de evidenciar uma intrincada rede de relações que se travam entre os diversos níveis gramaticais" (Cf. VIEIRA, 2004, p. 202). Ademais, será possível perceber que a fala constitui a manifestação linguística legítima e natural, e não menos importante que a escrita. A opção do aluno deve ser consciente, com base no (re-)conhecimento das variantes, para que o mesmo se utilize da ênclise quando o contexto permitir e ele assim o desejar.

Através de uma segura descrição científica, é possível, entre outros procedimentos, reconhecer na próclise o status de variante legítima, bem como reconhecer os contextos sociolinguísticos de uso restrito da ênclise (além de explicitar que a mesóclise, em desuso, é resultado de um processo de gramaticalização, por que passou o tempo futuro). Anteriormente de tudo, é preciso mudar a mentalidade repressora de alguns profissionais que pensam que, para se ter conhecimento da 
língua e valorizá-la, seja preciso partir do conhecimento teórico de algumas de suas mais detalhadas particularidades ou seguir modelos aleatórios, em vez de reconhecer seu uso e as múltiplas formas de emprego. Na verdade, essa mentalidade tem sido produtora de instrumentos de opressão linguística, pois, em vez de fazer com que o aluno se interesse por seu estudo, cada vez mais o afasta dele.

Além disso, há que se questionar o fato de que muitos materiais didáticos de hoje não têm como foco o domínio das diversas variedades e modalidades linguísticas, que vão do mais oral ao mais escrito; do mais informal ao mais formal, do mais rural ao mais urbano, conforme propõem os contínuos estabelecidos por Bortoni-Ricardo (2004) - oralidade-letramento, monitoração estilística, urbanização. Nesse sentido, a escola por vezes restringe-se a apresentar a variante tida como de prestígio em manuais normativos, não fazendo um trabalho com as diversas variantes dos fenômenos linguísticos.

De acordo com Vieira (2004), a escola deveria cumprir o propósito de oferecer ao aluno as normas de uso depreendidas a partir da realidade sociolinguística, de modo a possibilitar ao aprendiz o conhecimento do maior número possível de opções, respeitando-se os contínuos da variação e sem negar o estatuto social da linguagem, que é padronizador e variável a um só tempo. (VIEIRA; BRANDÃO, 2004, p. 204). Ao trabalhar com base em resultados sociolinguísticos, os professores teriam informações concretas a respeito dos contextos condicionadores dos usos linguísticos encontrados nas produções de seus alunos para, com base em tais resultados, apresentar reflexões mais seguras acerca não só dos fatores que favorecem, por exemplo, a preferência pela próclise em textos escritos, mas também do papel da escola no ensino da colocação pronominal.

\section{CONCLUSÃO}

Tomando por base os resultados da pesquisa, que confirmaram diversas hipóteses iniciais quanto ao uso e a ordem dos clíticos, percebe-se a influência da norma gramatical veiculada pela escola sobre a escrita dos estudantes, influência que se torna cada vez mais nítida consoante o aumento da escolaridade, o modelo implementado para cada tipo de texto e os contextos linguísticos.

Fazem-se necessárias reflexões diversas sobre a questão da norma e variação no ensino da língua materna. Além da aprendizagem de determinados clíticos, que não são adquiridos de forma natural no Português do Brasil, os resultados demonstraram que o conhecimento dos alunos dos contextos morfossintáticos em que a escrita padrão tem por opção preferencial a ênclise pode ser considerado fruto da influência dos meios escolares.

Com a implementação de tal conhecimento, não se pode negar que a escola acaba por ser fortemente reprodutora dos valores linguísticos e sociais das formas 
que adota, especialmente na modalidade escrita. É preciso assegurar, no entanto, que todo conhecimento linguístico divulgado pela escola deva colaborar com o aprimoramento do desempenho dos estudantes como leitores e produtores de textos, textos que são produzidos com diferentes estratégias linguísticas a depender da modalidade, do grau de formalismo e da variedade adotada. Além disso, considera-se que o ensino do uso e da ordem dos pronomes átonos deva levar o aluno a reconhecer os clíticos como recursos anafóricos importantes para a construção de um texto, falado ou escrito.

No caso do uso e da ordem dos clíticos pronominais, espera-se que, com base nesta pesquisa e nas diversas descrições sociolinguísticas desenvolvidas, os professores possam ter informações a respeito dos contextos condicionadores de cada variante para, a partir de tais resultados, desenvolver procedimentos que façam do aluno um eficiente usuário da língua nos diferentes contextos comunicativos a que diariamente é exposto.

Tais investigações apontarão os caminhos a serem seguidos para que se respeite a opção consciente dos alunos pelo uso de determinada variante em textos orais ou escritos e para que, em última instância, a escola cumpra seu papel educacional.

\section{REFERÊNCIAS BIBLIOGRÁFICAS}

BECHARA, Evanildo. Moderna gramática portuguesa. Rio de Janeiro: Lucerna, 2004 [1999].

BORTONI-RICARDO, Stella Maris. Educação em língua materna: a Sociolinguística na sala de aula. São Paulo: Parábola Editorial, 2004.

CORRÊA, Vilma Reche. Objeto direto nulo no Português do Brasil. 1991. Dissertação (Mestrado) - Unicamp, Campinas/SP, 1991.

CUNHA, Celso; CINTRA, Luis F. Lindley. Nova gramática do Português contemporâneo. Rio de Janeiro: Nova Fronteira, 1985.

DUARTE, Maria Eugênia Lammoglia. Variação e sintaxe: clítico acusativo, pronome lexical e categoria vazia no Português do Brasil. 1986. Dissertação (Mestrado) - PUC, São Paulo, 1986.

; CALLOU, Dinah (orgs.). Para a história do Português brasileiro, v. IV: Notícias de corpora e outros estudos. Rio de Janeiro: Faculdade de Letras/UFRJ, 2002.

; RAMOS, Jânia. O papel da Sociolinguística no ensino da escrita padrão. Revista do GELNE 5 (1 e 2), p. 91-96, 2003.

GALVES, Charlotte. Pronomes e categorias vazias no Português do Brasil. Cadernos de Estudos Linguísticos 7, p. 107-136, 1984.

. O objeto nulo no Português brasileiro: percurso de uma pesquisa. Cadernos de Estudos Linguísticos 17, p. 65-90, 1989. 
LABOV, William. The social stratification of English in New York Center. Washington, D.C.: Center for Applied Linguistics, 1966.

. Sociolinguistc patterns. Philadelphia: University of Pennsylvania Press, 1972. . Principles of linguistic change. v. 1. Oxford, Cambridge: Blackwell, 1994.

LEITE, Yonne; CALLOU, Dinah. Como falam os brasileiros. Rio de Janeiro: Zahar, 2002.

LOBO, Tânia. A colocação dos clíticos em Português: duas sincronias em confronto. 1992. Dissertação (Mestrado) - Universidade de Lisboa, Lisboa, 1992.

LUCCHESI, Dante. Norma linguística e realidade social. In: BAGNO, Marcos (org.). Linguística da norma. São Paulo: Loyola, 2002, p. 63-92.

MACHADO, Ana Carla Morito. O uso e a ordem dos clíticos na escrita de estudantes da cidade do Rio de Janeiro. 2006. Dissertação (Mestrado em Letras Vernáculas). Faculdade de Letras, Universidade Federal do Rio de Janeiro, Rio de Janeiro, 2006.

MATTOS e SILVA, Rosa Virgínia. O Português são dois: novas fronteiras, velhos problemas. São Paulo: Parábola Editorial, 2004.

MONTEIRO, José Lemos. Pronomes pessoais: subsídios para uma gramática do Português do Brasil. Fortaleza: Edições UFC, 1994.

NEVES, Maria Helena de Moura. Que gramática estudar na escola. São Paulo: Contexto, 2003.

NUNES, Jairo. Direção de cliticização, objeto nulo e pronome tônico na posição de objeto em Português Brasileiro. In: ROBERTS, Ian; KATO, Mary (orgs.). Português Brasileiro: uma viagem diacrônica. Campinas/SP: Editora da Unicamp, 1993, p. 207-222.

OMENA, Nelize Pires de. Pronome pessoal de terceira pessoa: suas formas variantes em função acusativa. 1978. Dissertação (Mestrado) - PUC, Rio de Janeiro, 1978.

PAGOTTO, Emílio Gozze. A posição dos clíticos em Português: um estudo diacrônico. 1992. Dissertação (Mestrado) - Unicamp, Campinas/SP, 1992.

PEREIRA, Maria das Graças Dias. A variação na colocação dos pronomes átonos no Português do Brasil. 1981. Dissertação (Mestrado) - PUC, Rio de Janeiro, 1981.

PERINI, Mario A. Para uma nova gramática do Português. São Paulo: Ática, 1985.

- Gramática descritiva do Português. São Paulo: Ática, 1995.

PINTO, Edith Pimentel. O Português do Brasil: textos críticos e teóricos 1 - 1820/1920, fontes para a teoria e a história. Rio de Janeiro: Livros Técnicos e Científicos; São Paulo: Edusp, 1978.

O Português do Brasil: textos críticos e teóricos 2 - 1920/1945, fontes para a teoria e a história. Rio de Janeiro: Livros Técnicos e Científicos; São Paulo: Edusp, 1981. ROCHA LIMA, Carlos Henrique da. Gramática normativa da Língua Portuguesa. 43. ed. Rio de Janeiro: José Olympio, 2003 [1972]. 
TARALLO, Fernando. A pesquisa sociolinguística. São Paulo: Ática, 1999.

VIEIRA, Silvia Rodrigues. Colocação pronominal nas variedades europeia, brasileira e moçambicana: para a definição da natureza do clítico em Português. 2002. Tese (Doutorado em Letras Vernáculas). Faculdade de Letras/UFRJ, Rio de Janeiro, 2002.

. O ensino da colocação pronominal: prescrição e uso. In: VIEIRA, Silvia Rodrigues; BRANDÃO, Silvia Figueiredo (orgs.). Morfossintaxe e ensino de Português: reflexões e propostas. Rio de Janeiro: Faculdade de Letras/UFRJ, 2004, p. 179-206.

; BRANDÃO, Silvia Figueiredo (orgs.). Morfossintaxe e ensino de Português: reflexões e propostas. Rio de Janeiro: Faculdade de Letras/UFRJ, 2004. 
